\title{
Experimental Research on the Influencing Factors of Radon Concentration Measurement in Soil
}

\author{
Yifan Jin, Junxin Zhang, Qiushi Liu \\ College of Nuclear Technology and Automation Engineering, Chengdu University of Technology, Chengdu, China \\ Email:jinyf29@sina.com
}

How to cite this paper: Jin, Y.F., Zhang, J.X. and Liu, Q.S. (2020) Experimental Research on the Influencing Factors of Radon Concentration Measurement in Soil. Open Access Library Journal, 7: e6657. https://doi.org/10.4236/oalib.1106657

Received: July 24, 2020

Accepted: August 17, 2020

Published: August 20, 2020

Copyright $\odot 2020$ by author(s) and Open Access Library Inc.

This work is licensed under the Creative Commons Attribution International License (CC BY 4.0).

http://creativecommons.org/licenses/by/4.0/

\section{(c) (i) Open Access}

\begin{abstract}
Radon is the most accessible radioactive gas in life. The radon in ambient air mainly comes from the soil. In order to ensure the accuracy and validity of the measurement of radon concentration in the soil, the paper discusses the influencing factors of the measurement of radon concentration in the soil through the controlled variable method. On the basis of familiarity with the principle of measuring the concentration of radon in the soil, using the radon meter to study the influence of the measurement depth, measurement period, soil type, fault and other factors on the measurement results in the actual measurement process, experiments show that the measurement depth maintained at $60-80 \mathrm{~cm}$ is appropriate; the measurement period has little effect on the measurement results, but measurement should be avoided in rainy days; different soil types have different effects on the measurement results, and the density and gap of the soil should be comprehensively considered; the radon concentration at the fault location will be obviously elevated.
\end{abstract}

\section{Subject Areas \\ Radiation Measurement}

\section{Keywords}

Soil, Radon Concentration, Influencing Factors, Measuring Depth

\section{Introduction}

There are two natural components of radon in the soil: one is the radon absorbed by solid substances or dissolved in liquid substances; the other is that it is not restricted by solid and liquid substances, radiates from these substances, and 
can accompany the migration and diffusion of other gases in the soil. The latter is the research object of measuring the concentration of radon in the soil, and this part of radon is also called soil radon [1].

The measurement of radon concentration in soil is used in many fields. The value of soil radon concentration can provide data reference and analysis for mineral exploration, geothermal research, volcanic eruption and earthquake prediction. The following factors will affect the distribution of radon concentration in the soil: 1) Diffusion of radon; 2) Convection of radon; 3) Suction effect; 4) Pumping effect; 5) Carrying effect of groundwater; 6) Geothermal effect; 7) Pressure of associated gas Function; 8) Ground stress; 9) The depth effect of atmospheric pressure leads to the migration of radon; 10) The effect of wind speed, direction and swirl on soil gas leads to the migration of radon [2]. The first to second influencing factors belong to the law of gas movement, and 3 to 10 belong to the influence of the characteristics of the earth's environment on the formation of soil radon concentration distribution. The distribution of radon concentration in soil is mainly affected by diffusion and convection.

The concentration of radon in the soil can provide data reference for mineral exploration, geological exploration, earthquake prediction, etc. The purpose of the paper is to analyze some factors that affect the measurement of radon concentration in the soil and find the relationship between them. Studying the factors affecting the measurement of radon concentration in the soil can obtain the measurement results more accurately and efficiently, and at the same time form a preliminary judgment on the level of radon concentration in the local air.

\section{Measurement and Calculation of Radon in Soil}

\subsection{Measurement Methods}

Commonly used methods for soil radon measurement include: ionization chamber method, scintillation chamber method, electrostatic collection method, solid track method, activated carbon adsorption method, etc. [2] [3]. To measure the concentration of radon in the soil, the main method in China is to drill holes with steel drills, and then extract the gas in the soil for measurement. This method is also commonly used in the world; this method of drilling and extracting air and then measuring is mainly It is used to do geological survey and search for underground uranium deposits, etc. [2].

The experimental instrument uses FD-3017RaA radon meter, as shown in Figure 1. The instrument is mainly used to measure the concentration of radon in the soil and the concentration of radon in the water. It consists of a console, an air pump, and a sampler; the sampler is inserted into the soil and the air pump is used to extract the radon in the soil. First, the moisture in the extracted gas is removed by a desiccant, so that the dried radon enters the gas cylinder, and the first generation radon decay daughter ${ }^{218} \mathrm{Po}(\mathrm{RaA})$ is collected with a metal sheet with negative high pressure. After pumping the air, let it stand for 10 - $20 \mathrm{~s}$, and place the metal sheet deposited with ${ }^{218} \mathrm{Po}$ on the gold-silicon surface 


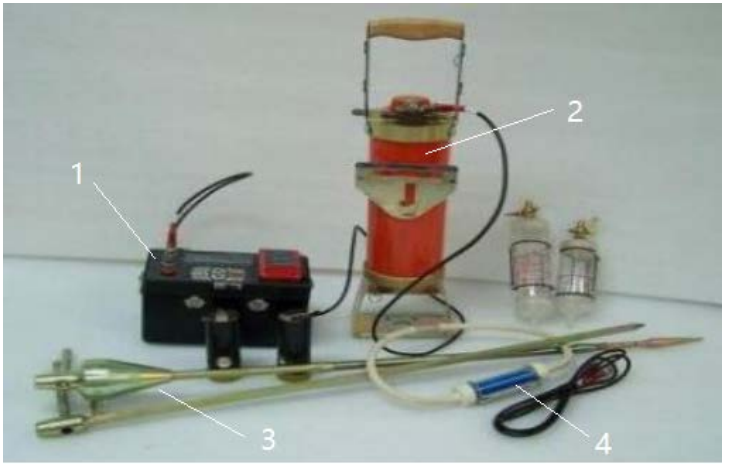

Figure 1. Radon measuring device diagram.

barrier semiconductor detector to measure the radioactivity concentration $(\mathrm{Bq} / \mathrm{L})$ of $\alpha$-rays [4].

Field measurement steps of the instrument:

1) Use the matching hammer and steel drill to drill holes at the placement position, the hole depth is $500 \mathrm{~mm}-800 \mathrm{~mm}$;

2) Pull out the steel drill after drilling, and then immediately insert the sampler into the sampling hole, step on the sampler close to the surface to prevent outside air from entering;

3) Put the collection piece: put the side of the collection piece with words up and put it into the suction pump;

4) Pumping: Turn the valve to "pump" and pump out slowly and at a constant speed;

5) Start high-pressure collection RaA: add high-pressure collection time for 2 minutes;

6) Take the slice and measure: After the high pressure is over, quickly take the slice and put it into the gold-silicon surface barrier detector within 15 seconds. During the slice removal process, avoid finger contact with the surface of the collection slice. The measurement time is two minutes.

As shown in Figure 1, the device numbered 1) in the figure is the console, which can be used for counting, threshold adjustment, high-voltage input, etc.; 2 ) is the detector part; 3 ) is the sampler, which is connected to the detector, and it is used for measurement. Insert the soil; 4) is a drying tube, using silica gel particles as a desiccant.

\subsection{Calculation Equations}

Radon concentration calculation:

$$
C_{R n}=K_{R n} \times X_{R n}
$$

In the above formula: $C_{R n}$-is the radon concentration value, $\mathrm{Bq} / \mathrm{m}^{3} ; K_{R n}$-is the calibration coefficient (scale factor) of the instrument, Bq. ${ }^{-3} \cdot \mathrm{min}^{-1} ; X_{R n}$-is the instrument reading value, $\mathrm{min}^{-1}$.

The scale coefficient of the experimental instrument $K_{R n}=141.6$ $\left(\mathrm{Bq} / \mathrm{m}^{3} \cdot\right.$ piece $\left.^{-1}\right)$. 


\section{Experiment and Analysis of Influencing Factors in Measuring Radon Concentration in Soil}

The experiment explores the influence of factors such as measurement depth, measurement period, measurement times, soil type, and fault location on the measurement of radon concentration in soil through the controlled variable method; in the process of the experiment, it is necessary to keep other conditions as consistent as possible when exploring a certain factor. Taking into account that each punching measurement can pump up to 3 to 4 times, it is necessary to punch multiple times in the same area.

The experiment is divided into two parts. One part of the experiment is mainly to measure relevant data on the campus. In addition, in the process of following the Sichuan Provincial 403 Geological Team's geological survey on the expansion project of Zhaojue County. During the period, it can conduct farmland (line 2) and mountainous areas in similar areas. Line 1), Line 3 and the faults in each of them are measured; it can provide sufficient data basis for experimental research.

At the end of the experiment, the data was screened and sorted; through the analysis of the data, the influence of the measurement depth, measurement period, soil type, and fault location on the measurement of soil concentration was summarized.

\subsection{The Effect of Measuring Depth}

According to the experimental instrument, the different measuring depths of the same area: $20 \mathrm{~cm}, 40 \mathrm{~cm}, 60 \mathrm{~cm}, 70 \mathrm{~cm}, 80 \mathrm{~cm}$, are compared in experiment. Before drilling, Use a tape measure and a marker to make marks of different depths on the steel drill, and insert the soil to different depths according to the marks. The measurement results are as follows (Table 1 and Figure 2).

According to the analysis of the data:

With the increase of depth, the overall trend of the measured value of soil radon concentration will gradually increase; when the depth is in the interval of 20 $\mathrm{cm}-60 \mathrm{~cm}$, the increase of the concentration with depth is relatively large, and the increase in the interval of $60 \mathrm{~cm}-80 \mathrm{~cm}$ is relatively gentle; this effect It is

Table 1. Different measuring depth experimental data.

\begin{tabular}{cccccc}
\hline & \multicolumn{5}{c}{ Radon concentration values at different measuring depths $\left(\mathrm{Bq} / \mathrm{m}^{3}\right)$} \\
\cline { 2 - 6 } Location & $20 \mathrm{~cm}$ & $40 \mathrm{~cm}$ & $60 \mathrm{~cm}$ & $70 \mathrm{~cm}$ & $80 \mathrm{~cm}$ \\
\hline No.9 Building on Campus (A) & 566 & 850 & 1133 & 1133 & 1274 \\
Campus Venture Park (B) & 850 & 991 & 1416 & 1558 & 1558 \\
A farmland (C) & 1558 & 1416 & 1699 & 2549 & 2832 \\
A mountain (D) & 1699 & 2266 & 2832 & 3398 & 3540 \\
A fault (E) & 9062 & 13,594 & 15,859 & 16,992 & 17,558 \\
\hline
\end{tabular}




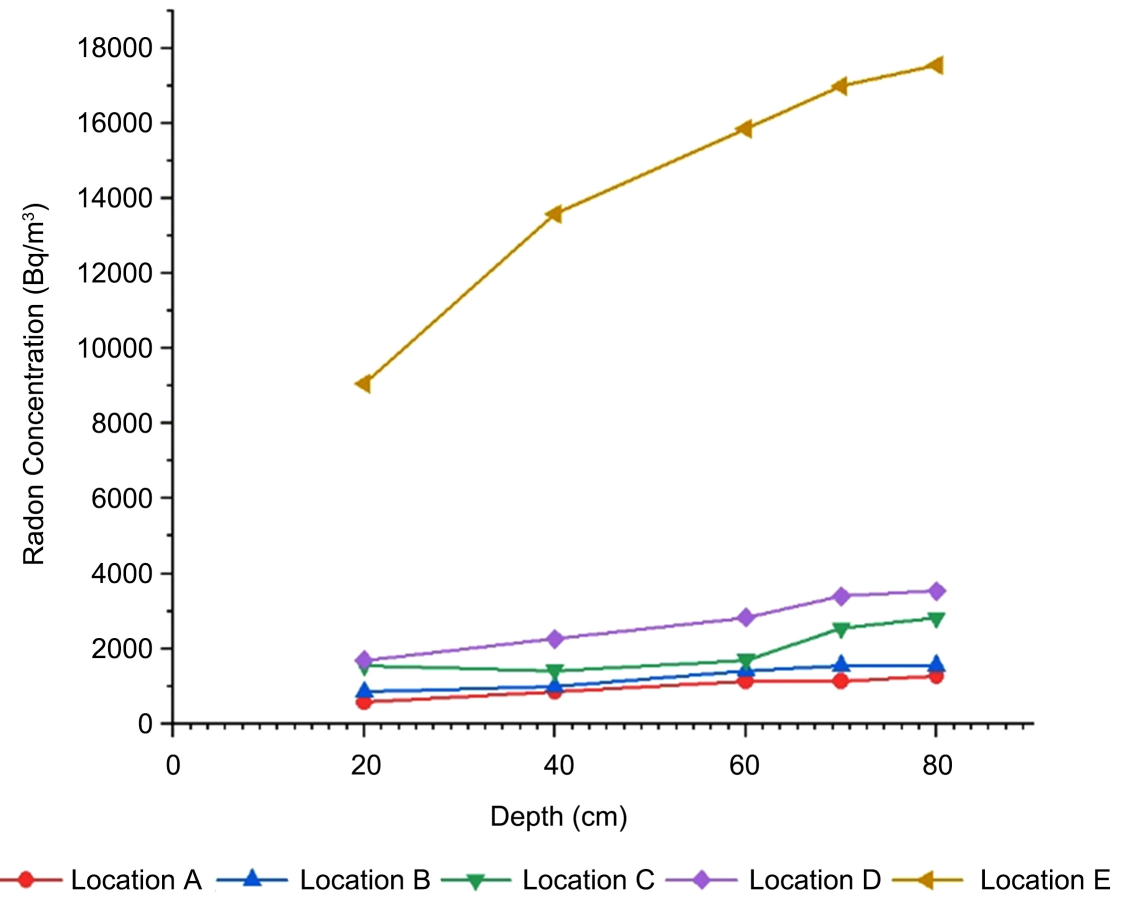

Figure 2. Measurement depth analysis graph.

more obvious in locations with high radon concentration (such as geological faults). At the location of the fault, it can be clearly seen that the radon concentration in the soil changes gradually with the depth of the soil; therefore, we can conclude that the deeper the measurement depth. The measurement result of the soil radon concentration value will be larger. However, in the actual measurement process, due to the limitation of the measurement conditions and the factors of the underground rock, it is impossible to drill the measurement hole to a few meters or deeper. According to the analysis, the measurement depth should be It is suitable between $60 \mathrm{~cm}-80 \mathrm{~cm}$.

\subsection{Influence of Measurement Period}

At multiple points, sample and analyze the three time periods in the morning, noon, and evening to ensure that the morning is from 7:00 to 8:30, the noon is from 12:00 to $13: 30$, and the evening is from 18:00 to 17:30 time periods; the same point ensures the same measuring depth;

The measurement results are as follows (Table 2 and Figure 3).

According to the analysis, the radon concentration in the soil will change in the morning, noon and evening, but there is no big difference in the measurement results of the three different periods, and the magnitude of the change is very small. It can be seen in the line graph that the morning, noon, and evening The broken line formed by the radon concentration values in the soil at the same point in the three periods is basically a straight line; therefore, the influence of the three different periods in the morning, noon, and evening on the measurement of the radon concentration in the soil is basically zero. 
Table 2. Experimental data table for different periods.

\begin{tabular}{cccc}
\hline \multirow{2}{*}{ Location } & \multicolumn{3}{c}{ Radon concentration values in different measurement periods $\left(\mathrm{Bq} / \mathrm{m}^{3}\right)$} \\
\cline { 2 - 4 } & Morning & Middle & Evening \\
\hline Library lawn (A) & 850 & 991 & 991 \\
West Gate Garden (B) & 1699 & 1558 & 1841 \\
2 - 020 Farmland (C) & 2407 & 2549 & 2266 \\
2 - 116 Fault (D) & 6838 & 7080 & 7080 \\
$1-140$ Mountain (E) & 2832 & 2832 & 2974 \\
\hline
\end{tabular}

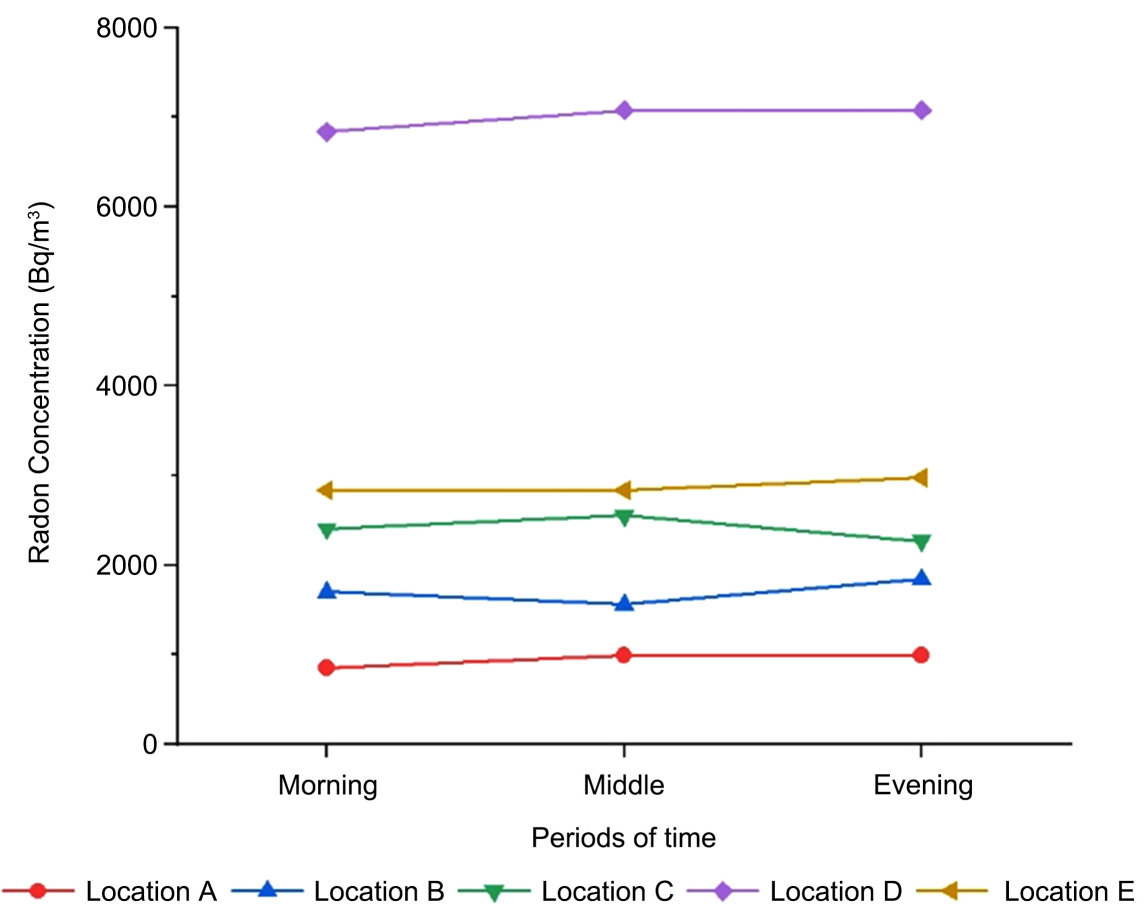

Figure 3. Data analysis line chart of measurement period.

Reason analysis: The concentration of radon in the soil is mainly related to the uranium, thorium, and potassium in the soil. Although the atmospheric pressure and external humidity in different measurement periods are different, there is isolation between the soil and the ambient air, and the difference in the external atmospheric environment is not It will have a big impact on the radon concentration in the soil; in addition, FD-3017 counts RaA and then uses the scale factor to convert the radon concentration value. One count of the instrument represents $141.6 \mathrm{~Bq} / \mathrm{m}^{3}$, so the slight impact cannot be reflected; in summary, under normal conditions except rainy days, the concentration of radon in the soil can be measured in the morning, noon, and evening.

\subsection{Influence of Soil Type}

140 points were measured near Zhaojue County. Based on the calculation re- 
sults, the average radon concentration level was around $2500 \mathrm{~Bq} / \mathrm{m}^{3}$ (background value) except for the fault location. On this basis, mountain, farmland, and farmland were selected. Riverbed, sandy land, and backfilled soil for experimental research. During the experiment, ensure that the measurement depth, measurement period, and number of pumping times are the same.

The measurement results are shown in Table 3.

According to the measurement results and background values, make a scatter plot of the data for comparative analysis; Figure 4 shows that in the mountains, uncultivated farmland, and uncultivated farmland, the radon concentration in the soil is measured at an average radon concentration of $2500 \mathrm{~Bq} / \mathrm{m}^{3}$ up and down; and for the cultivated land, riverbed, sandy land, backfilled soil, etc., the measurement result of the radon concentration in the soil is significantly lower than the background value.

Table 3. Measurement data for different soil types.

\begin{tabular}{ccccc}
\hline Number & Soil type & Reading & $\begin{array}{r}\text { Radon concentration } \\
\left(\mathrm{Bq} / \mathrm{m}^{3}\right)\end{array}$ & $\begin{array}{c}\text { Background } \\
\left(\mathrm{Bq} / \mathrm{m}^{3}\right)\end{array}$ \\
\hline 1 & Mountain 1 & 19 & 2690 & \\
2 & Mountain 2 & 15 & 2424 & 2500 \\
3 & Farmland & 12 & 1699 & \\
4 & Cultivated land (uncultivated) & 16 & 2265 & \\
5 & Cultivated land (plowed) & 8 & 1132 & \\
6 & Riverbed & 6 & 850 & \\
7 & Sand & 5 & 708 & \\
8 & Backfill & 7 & 991 & \\
\hline
\end{tabular}

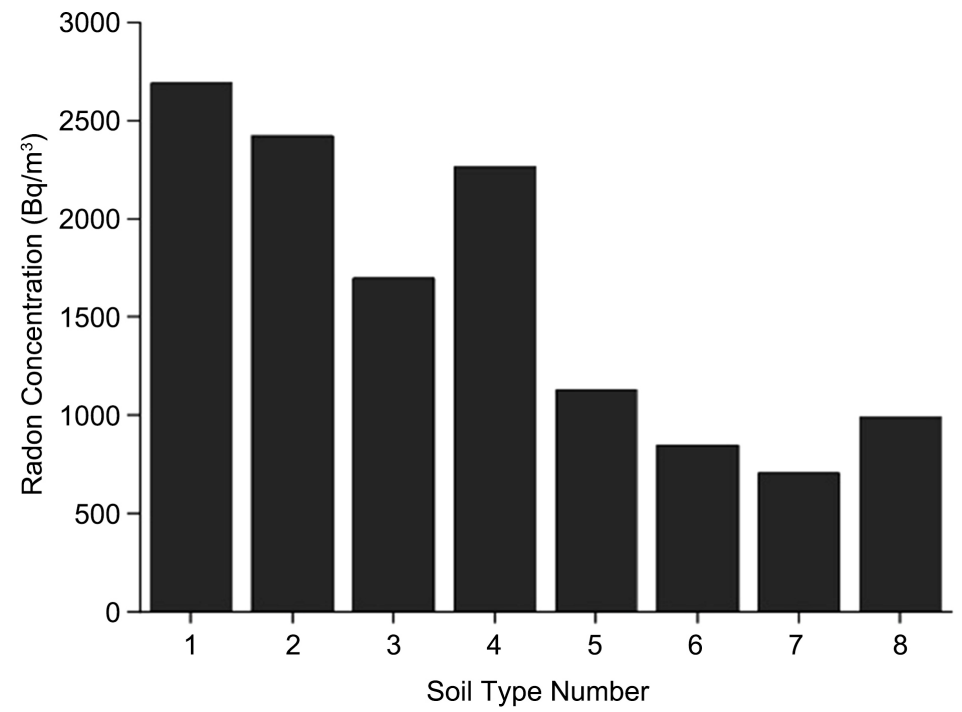

Figure 4. Radon concentration in different soil types. 
Analysis: radon exists in the form of gas in shallow soil, so it will diffuse like other gases, so different soil densities, different sizes of soil gaps, and human factors will affect its concentration.

For mountainous soils, because there are relatively more rocks in the mountains, there will be more radon gas released from the rock formations, and there is no human activity influence, so the soil radon gas is in normal diffusion, so the measured value of the radon concentration in the soil. There will be no big differences in the mountains.

Farmland and uncultivated arable land, due to human activities, planting, crop roots, etc., will have some strengthening effect on the diffusion of radon in the soil, and because it has been deposited for a period of time after plowing, its influence will not be too great, and the measured value will not have a big difference.

Plowed cultivated land, due to human influence, causes the surface soil of the cultivated land to become looser, which is conducive to the diffusion of radon in the soil in the area into the ambient air, which will cause the concentration of radon in the soil in the area for a period of time The measurement results of the riverbed and sandy land are relatively low; the radon in the soil is more likely to diffuse into the ambient air due to the large gaps in the riverbed and sandy land, resulting in a decrease in the concentration of radon in the soil, so the measurement result will be low. The backfill soil is the soil that has been transported and backfilled. During the transport process, the radon gas in it will diffuse into the air, so its concentration will definitely be lower than the background value.

Summary: For mountains, farmland, arable land, riverbeds, sandy land, and backfilled soil, different soil types will have a certain impact on the measurement results of radon concentration in the soil. The measured value of radon concentration in soils with human activities, excessive soil density, large soil gaps, and well-developed plant roots will be relatively small, so the measured data is not sufficiently representative; therefore, in the actual measurement process, Accurately reflect the soil radon concentration value in an area. The above factors should be taken into account when placing the points. If necessary, these locations should be avoided or the measurement points should be added to obtain the average value.

\subsection{Influence of Faults}

According to the radon concentration measurement results of the three measurement lines in Zhaojue County, compare the difference of the radon concentration in the soil at the fault location, and draw a line graph.

Analysis: It can be seen from Figure 5 that the radon concentration value in the soil at the fault location is obviously too large. Crossing the fault location, the radon concentration value in the soil will gradually decrease and then stabilize; and for different faults, the corresponding measurement of the radon concentration in the soil There is also a big difference in the value, which is related to the 


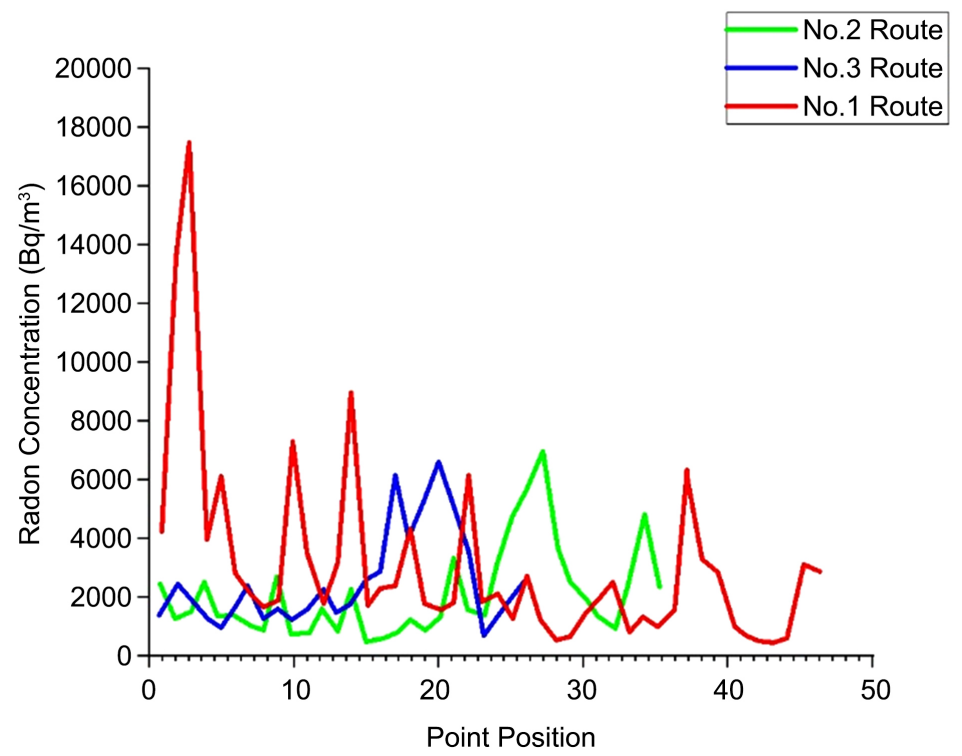

Figure 5. 3 lines measurement data line graph.

thickness of the faulted soil cover, whether it is an active fault, and the width of the fault; theoretically, the thicker the faulted soil cover, the smaller the measurement result of the radon concentration in the soil. The measured value of active faults is larger than that of inactive faults; the larger the width of the fault, the larger the corresponding measured value.

Therefore, the concentration of radon in the soil can also provide a reference value for the determination of the location of geological faults. By measuring the concentration of radon in the soil, the surface fault map can be surveyed; in the actual measurement process, if the measured value suddenly increases. The abnormal point should be taken as the center to measure the radon concentration in the surrounding soil. If the abnormal area shows a certain pattern, the measurement points should be appropriately increased, relevant records should be made, and the data should be analyzed to find out the cause of the abnormal measured value and analyze whether it is related to geological faults.

\section{Conclusion}

In summary, the measurement depth, soil type, faults, etc. will all have different effects on the measurement results of radon concentration in the soil. According to experimental research, in the actual measurement process, in order to ensure the validity and accuracy of the measurement results, the measurement depth should be maintained in the range of $60 \mathrm{~cm}-80 \mathrm{~cm}$; when measuring in non-cloudy and rainy days, the measurement of radon in the soil will not be affected at different time periods; the concentration of radon in soil with large gaps such as sandy soil is lower; the value of soil radon concentration in the fault location is larger; if it is encountered during the measurement process when it rains, the measurement should be carried out 24 hours after the rain; for the field data record, it should include the point map, soil type, point location, and a 
basic description of the ground surface of the measurement site, as a reference basis for later data analysis.

\section{Conflicts of Interest}

The authors declare no conflicts of interest regarding the publication of this paper.

\section{References}

[1] Mao, X.H. (2013) Determination of Soil Radon Concentration in Construction Sites and Discussion on Its Influencing Factors. "Construction Technology and Management" Organizing Committee. Proceedings of the July 2013 Construction Technology and Management Academic Exchange Conference, Beijing Hengsheng Boya International Cultural Exchange Center, 170-171.

[2] Gao, C. (2008) Research and Application of Soil Radon Concentration Measurement and Correction Method. Chengdu University of Technology, Chengdu.

[3] Deng, L.L. (2006) Research on Radon Measurement Method and its Application in Environmental Detection. Chengdu University of Technology, Chengdu.

[4] Sun, B.S., Zhang, J.Y., Zhou, Z.J., Hu, M.K. and Du, X.L. (2015) Evaluation of Measurement Uncertainty of FD-3017 Radon Meter. Science and Technology Innovation Herald, 12, 66-67. 